\title{
An assessment of anaerobic digestion capacity in Bangladesh
}

Khondokar M Rahman ${ }^{1,2}$, Ryan Woodard ${ }^{2}$, Elizabeth Manzanares ${ }^{2}$ and Marie K Harder ${ }^{1 *}, 2$

${ }^{1}$ Department of Environmental Science and Engineering, Fudan University, 220

Handan Road, Shanghai, 200433 China

${ }^{2}$ Waste and Energy Research Group, School of Environmental Science and Technology, University of Brighton, Cockcroft Building, Lewes Rd., Brighton, UK, BN2 4GJ

Corresponding Author: Prof. MK Harder, m.k.harder@ brighton.ac.uk, tel +44 (0)7960051439 or +8618221867042

\begin{abstract}
This work scopes the potential for existing common feedstocks to be used in existing types of anaerobic digester units to produce biogas in Bangladesh. A preliminary study identified three commonly occurring scenarios of smallholdings with cattle, poultry farms and daily cattle markets, which produce dung, poultry litter, and dung mixed with rice straw respectively. This third feedstock is proposed as a novel and significant newly recognised prevalent source. The main study involved carrying out surveys of representative samples of each of these $(\mathrm{N}=125,125,30)$ for the district of Gazipur in order to determine the distribution of herd and flock sizes, and thus the relevant biogas plant types and potential yields. The results were scaled up for nationwide figures, which approximated the total potential biogas energy from these feedstock types at $240 \times 10^{6} \mathrm{MJ}(240 \mathrm{TJ})$ per day, or $66.7 \mathrm{x}$ $10^{6} \mathrm{kWh}$, which in principle could meet the current cooking energy requirements of 30 million people in Bangladesh. Of this, $70 \%$ of the potential energy from AD could come from cattle feedstock (with $87 \%$ of this from domestic-sized plant); $16 \%$ from poultry feedstock (with $63 \%$ of this from medium-sized plant); and $14 \%$ from rice straw bedding from cattle markets (all requiring large or very large plant). There is potential for around 2 million domestic units, 340,000 medium units and 20,000 large or very large units that might be more suited for larger users such as businesses, schools or hospitals.
\end{abstract}

\section{Keywords:}

Anaerobic digestion, biogas, Bangladesh, energy, feedstock, domestic 


\section{Introduction}

\subsection{Geographical information for Bangladesh}

Bangladesh is one of the least developed and most densely populated countries in the world [1], with a land area of 147,570 square kilometres and a population density of 1,063 people per square kilometre, with an income per capita $1 / 100^{\text {th }}$ of the UK [2]. A humid, lowlying, alluvial region, Bangladesh is composed mainly of the great combined delta of the Ganges, Brahmaputra, and Meghna rivers. Except for the Chittagong Hills along the Myanmar border, most of the country is less than 90 meters above sea level.

\subsection{Energy status}

The population of over 144 million people faces severe problems of environmental degradation, shortage of food supply, reduction of soil fertility and scarcity of energy [3]. The economy of Bangladesh is agriculture-based, with more than $60 \%$ of the workforce engaged in agriculture [4], and agriculture contributes about half of the Gross Domestic Product (GDP). Per capita electricity consumption is only $146.5 \mathrm{kWh}$ in Bangladesh, whereas in India it is $480.5 \mathrm{kWh}$, and in Pakistan, it is $456.2 \mathrm{kWh}$, and for developed countries the average per capita electricity consumption is $8009.5 \mathrm{kWh}$ [5].

Except for natural gas found along its eastern border, limited quantities of oil in the Bay of Bengal, coal, and some uranium, Bangladesh possesses few fossil fuel reserves. More than $55 \%$ of the country's energy requirement comes from traditional biomass energy sources, which are crop residues, twigs, leaves, firewood and dung cake [6]. Traditional biomass energy is used mostly for cooking. Excessive use of biomass energy causes deforestation and in the long run increases the likelihood of environmental disasters like cyclones and floods, compromising agricultural productivity and economical development $[6]$.

Commercial energy consumption comes from around $66 \%$ natural gas, met by the country's reserves of natural gas, and the other $34 \%$ by oil and limited amounts of hydropower and coal. The gas is used in the manufacturing of fertiliser, generation of electricity, direct use in certain industries, and as cooking fuel in major urban areas. Economically, it is not feasible to supply the gas to the rural areas through pipelines. Petroleum products such as high speed diesel oil and superior kerosene oil are the main fuel for transport and rural lighting [4]. 


\subsection{Waste scenario and management}

Every day 3,500 tonnes of waste is produced in Dhaka, the capital of Bangladesh. This includes Municipal Solid Waste (MSW), agricultural waste and a minor amount of animal waste (cattle dung and poultry litter) [7]. Annually, 511,000 tonnes of waste are disposed at simple controlled landfills near Dhaka, and 509,248 tonnes per year are 'lost' or illegally dumped [8]. In cities, the government and the City Corporations collect only $42 \%$ of waste for disposal in landfill: much can be found on roadsides, near open drains, and in the low-lying areas of the city [9]. The dumping of this waste has led to major environmental problems like transmission of diseases, greenhouse gas emissions (GHG) and pollution of ground water [10].

Apart from Dhaka city in the rural areas, many people have either domestic or commercial cattle and/or poultry farm. In many cases an open storage of cow dung in smallholdings can create breeding grounds for mosquitoes and causes disease [11]. Inadequate collection and uncontrolled disposal of waste creates a serious health hazard to inhabitants and the environment in Bangladesh [12] and a major and growing environmental problem worldwide in developing countries [13].

Apart from landfill, composting of household waste and anaerobic digestion of animal manure are the two major common practices relating to organic waste in Bangladesh. Both serve to stabilise organic waste, make it hygienic, and reduce its mass. Furthermore, they facilitate the return to the earth of organic compounds and some nutrients. Anaerobic digestion processes can also be designed to allow the collection of a useful amount of biogas, even when waste management is the main purpose. Composting and digestion can be used as complementary approaches, depending on parameters such as the kind and variety of waste material; anaerobic and aerobic steps may also be combined in one treatment facility [14]. Climate change has been a significant recent driver leading to a move away from the landfilling of biodegradable wastes (a major source of methane emissions) and to a renewed focus on energy recovery from waste [15]. Due to these multiple potential benefits of waste management, GHG control, potential energy production and possible nutrient production, $\mathrm{AD}$ has become an important option for developed and developing countries. 


\section{Current management methods of cattle dung, poultry litter and cattle market straw}

Most non-urban families have a 'smallholding', including a few cattle where possible, and their dung is collected and dried for fuel. This dung cake is used for cooking. Poultry litter are thrown away in the nearest field and causes environmental and land pollution. A small amount of cattle dung and poultry litter is used as a biogas feedstock [6]. However cattle market rice straw mainly goes to the landfill.

\subsection{Anaerobic digestion}

Anaerobic digestion (AD) is a biological process of the breakdown of organic matter by naturally occurring bacteria in the absence of air, and this produces biogas and a solid digestate. Biogas comprises of mostly methane and carbon dioxide with a small amount of hydrogen sulphide and hydrogen. Depending on the type of input material, the residual solid matter or digestate can be a nutrient-rich bio-fertiliser [16]. According to a report by the Bangladesh Centre for Advance Studies [17], the 8.44 million households of Bangladesh have 22.29 million cattle and buffalo, and there are 116, 000 poultry farms which produce 22,139 tonnes of litter per day. Traditional use of dung and litter has a big impact on the environment and cultivable land in Bangladesh because when it is dumped on low ground adjoining dwelling areas it causes them to be affected by smell, dust and surface water pollution [18]. Bangladesh already has nearly 40,000 domestic biogas plants using cow dung or poultry litter, but the full potential has been estimated at 3 million plants [6].

Bangladesh has a suitable climate for biogas production. The ideal temperature for biogas is around $35^{\circ} \mathrm{C}$. The temperature in Bangladesh usually varies from $6^{\circ} \mathrm{C}$ to $40^{\circ} \mathrm{C}$, but the internal temperature of a biogas digester in Bangladesh usually remains at $22^{\circ} \mathrm{C}$ to $30^{\circ} \mathrm{C}$, which is very near to the optimum requirement [19]. Suitable raw feedstocks for biogas such as cow dung and poultry litter are easily and cheaply available throughout the country.

The potential for mass deployment of domestic AD plants is very promising. Government and micro-finance companies already support such schemes. The use of AD could supply a much-needed energy resource for domestic consumption for cooking, as well as bio-fertiliser to enrich the farm land. It would also reduce deforestation by displacing wood fuel, and improve air quality in rural homes by avoiding contributions caused by incomplete combustion of solid fuels. These AD plants would be situated in rural farm areas 
where there is no realistic option for extending natural gas supply, on smallholdings where the energy would be directly used.

The common use of $\mathrm{AD}$ biogas in Bangladesh would also make a significant contribution to the reduction of greenhouse gases, which could provide some income via the Clean Development Mechanism (CDM). However, this approach would require appropriate calculation of baseline carbon emissions.

The focus of this study is the determination of the potential energy contribution and energy patterns of small and medium AD systems in Bangladesh from common feedstocks and common scenarios.

\section{Overall methodology}

To determine the scope of currently available AD opportunities in Bangladesh, three strands of methodology were developed. Firstly, preliminary exploratory investigations were used to determine the most common scenarios in the country which could provide appropriate feedstocks. Secondly, representative surveys were undertaken in one district of Bangladesh to determine the size distributions of potential $\mathrm{AD}$ plant for each scenario in that district. Thirdly, the results were scaled up for nationwide figures. More details of each are given in the appropriate sections below.

\section{Exploratory study to determine most common scenarios}

In order to first determine the most common scenarios which could provide immediate opportunities for $\mathrm{AD}$, it was decided to obtain an overview of common organic waste streams and existing AD practices of Bangladesh through initial exploratory field visits and meetings with key government and non-governmental organizations of Bangladesh. These included Grameen Shakti (GS), Advance Engineering (AE), Bangladesh Council for Scientific and Industrial Research (BCSIR), Netherland Development Organization (SNV) and Infrastructural Development Company Limited (IDCOL). Those organizations are key sources of related data and are deeply involved with AD research through contributing field and laboratory facilities in Bangladesh. Grameen Shakti also provided access to a number of $\mathrm{AD}$ sites for visits for this research.

From these explorations and also literature searches it was found that common scenarios included smallholdings with cattle, poultry farms, municipal waste (i.e. the organic elements) and water hyacinths. However, it was recognized that municipal waste could not 
provide the reliable homogeneity and constant supply required for effective $\mathrm{AD}$, and that water hyacinths are not available all year round (although they are a prolific source of material at certain times of the year). One of the authors also individually proposed a new scenario: daily cattle markets held in towns, which produce regular amounts of rice straw mixed with dung. The final three common scenarios which showed most promise were then surveyed: cattle from smallholdings, poultry farms and cattle markets.

From the exploratory work it was noted that the daily AD feedstock produced and collected per animal could vary significantly depending on their age and condition, food habits, and whether left free to wander or kept inside. For consistent calculations in this work, secondary data was used, summarized in Table 1.

Table 1

Secondary information on typical AD feedstock production rates for cattle, poultry and cattle in markets

\begin{tabular}{lcl}
\hline AD feedstock sources & $\begin{array}{c}\text { Feedstock production } \\
\text { (kg/animal/day) }\end{array}$ & $\begin{array}{l}\text { Source of information } \\
\text { (in this work) }\end{array}$ \\
\hline Cattle & 10 & {$[24]$} \\
Poultry & 0.1 & Grameen Shakti [27] \\
Cattle in town markets & 35 & Advance Engineering [29] \\
\hline
\end{tabular}

\section{Surveys of smallholdings, poultry farms and cattle markets}

A survey to identify the feedstock capacity of Gazipur district for the three scenarios was carried out. Bangladesh consists of 64 districts with 507 sub-districts, and each subdistrict has a large number of cattle smallholdings and poultry farms of varying capacity [20]. Moreover, reliable quantitative data for each district are not available. Research conducted by Wilson et. al., [21] found that quantitative data on waste research were generally scarce and unreliable in developing countries. It was thus decided to collect primary data via surveys across each sub-district of one district, and Gazipur was chosen since one of the authors was very familiar with it. A total of 280 sampling surveys were carried out: for each of the five sub-districts this included 25 cattle smallholdings, 25 poultry farms, and all known cattle markets. 
Each sub-district is made up of several hundred Unions (which in turn are made up of small communities). In each sub-district, Unions representing more or less the geographic centre, north, south, east and west areas were selected, and 5 smallholdings and 5 poultry farms were randomly selected in each of those. All known cattle markets were visited $(\mathrm{N}=30)$.

During the survey, smallholdings with a cattle population of less than 3 were not included because the daily requirement of biogas for cooking purposes for an average sized (5 person [24]) family is $2 \mathrm{~m}^{3}$, requiring at least 5 cattle. However, smallholdings of 3-4 cattle were also included in this survey for two reasons. Firstly, they can produce around 1 $1.5 \mathrm{~m}^{3}$ of biogas daily, meeting the requirements of a small family (3 - 4 people/family) [24]. Secondly, the exploratory study revealed that there are a number of $2 \mathrm{~m}^{3} \mathrm{AD}$ plants in Bangladesh currently operating which only have 3-4 cattle per smallholding. Additional information was collected for each site in the survey such as if there is an existing on-site biogas plant, the plant size, the food habits of the animals, and any uses of gas and slurry and other products.

It was decided to use three $\mathrm{AD}$ plant sizes for reference as they are generally available: domestic (D) for $2-5 \mathrm{~m}^{3}$, medium (M) for $5-25 \mathrm{~m}^{3}$ and large (L) for $25-150 \mathrm{~m}^{3}$ of biogas daily [22]. In fact our data was found later to imply the usefulness of both a smaller and a larger plant, of $<2 \mathrm{~m}^{3}$ and $>150 \mathrm{~m}^{3}$ respectively, and which we labelled as 'small domestic' and 'very large'.

\subsection{Survey results of cattle in smallholdings}

In each of five sub-districts of Gazipur, 25 smallholdings were randomly surveyed, altogether showing a total cattle population of 1,118 cattle across 125 smallholdings. The herd size distribution is shown in Table 2 below.

Table 2

The number of smallholdings with different sized herds in Gazipur district $(\mathrm{N}=125$. Note that only those with 3 or more cattle were recorded.)

\begin{tabular}{lcc}
\hline Number of cattle & No of smallholdings & \% smallholdings \\
\hline $3-5$ & 54 & 43 \\
$6-10$ & 48 & 38 \\
\hline \hline
\end{tabular}




$\begin{array}{lcc}11-15 & 8 & 7 \\ 16-20 & 5 & 4 \\ >21 & 10 & 8\end{array}$

Table 2 shows that most (81\%) of cattle smallholdings have a cattle population of 3 10, which is useful for planning appropriately sized AD plants. In terms of cumulative quartiles, $25 \%$ of the smallholdings were found to have $\leq 4$ cattle, $50 \%$ of them $\leq 5$ cattle, and $75 \% \leq 8$ cattle. The highest number of cattle found in a smallholding was 54 . Any with less than 3 cattle were not included.

Table 3 shows the distribution of smallholdings by potential AD plant size. The daily energy requirement for cooking purposes is $44 \mathrm{MJ} /$ household of 5 members [23]. Assuming the value of $8.1 \mathrm{MJ}$ of biogas/animal daily [24] our survey result shows that $29 \%$ of smallholdings have a capacity to produce up to $2 \mathrm{~m}^{3}$ of biogas daily (i.e. less than the size of the smallest commonly available $\mathrm{AD}$ unit) and can generate only $29 \mathrm{MJ}$ of energy. This is only sufficient for a family which is smaller than average (i.e. 3-4 instead of 5), but on the basis of this data indicating the availability and usefulness of this new smaller category of plant, we added it to our considerations and labelled it 'small domestic' plant. The survey data showed that an additional 58\% of cattle smallholdings have potential for domestic sized biogas plant with yield rates of $2-5 \mathrm{~m}^{3}$ daily (domestic size).

A further $13 \%$ of smallholdings were found to yield potential capacity of $5-25 \mathrm{~m}^{3}$ (medium size), with a daily average of $232 \mathrm{MJ} / \mathrm{smallholding.} \mathrm{This} \mathrm{amount} \mathrm{of} \mathrm{energy} \mathrm{can} \mathrm{meet}$ the cooking energy requirements for up to 5 families collectively.

Table 3

Cattle smallholding distribution by AD plant size (from survey results, $\mathrm{N}=125$ ) in Gazipur district.

\begin{tabular}{ccccc}
\hline AD type & $\begin{array}{c}\text { Biogas yield } \\
\left(\mathbf{m}^{\mathbf{3}}\right)\end{array}$ & $\begin{array}{c}\text { \% of } \\
\text { smallholdings }\end{array}$ & $\begin{array}{l}\text { Average } \\
\text { Cattle/smallholding }\end{array}$ & $\begin{array}{c}\text { Average daily } \\
\text { MJ/smallholding }\end{array}$ \\
\hline Small & $(<2)$ & 29 & 3.5 & 29 \\
\hline \hline
\end{tabular}


domestic

Domestic

$(2-5)$

58

7

57

Medium

$(5-25)$

13

28.6

232

Note that these calculations are based on a published yield capacity which is appropriate for optimal operational conditions (10 kg per cattle per day, [24]).

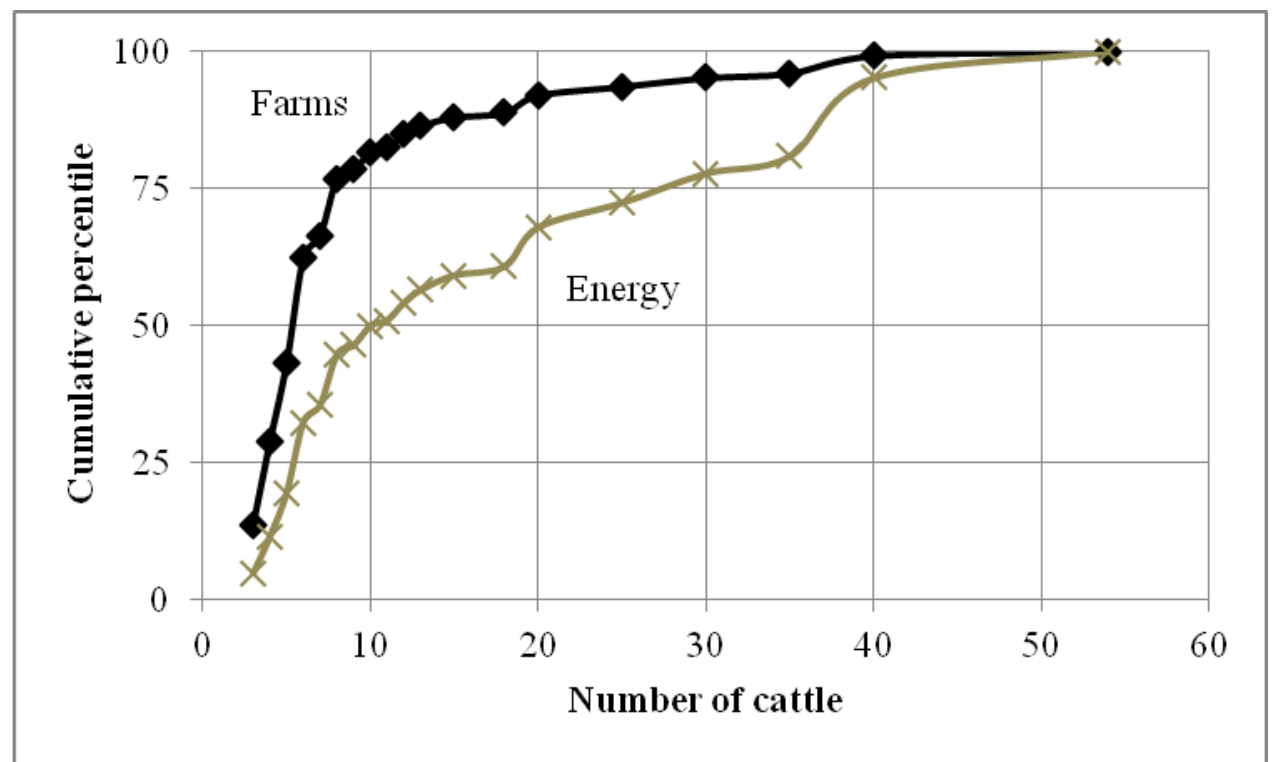

Figure 1. Cumulative percentile of the number of smallholdings ('farms') and their energy potential with respect to the number of cattle on each farm, for Gazipur district (from survey results).

Figure 1 introduces cumulative information not only for the herd sizes but also for the energy outputs possible. It illustrates useful combinations of information e.g. that $50 \%$ of AD energy capacity of cattle smallholdings comes from cattle those with $\leq 9$ cattle, which is $80 \%$ of the total number of farms. This means that even if only domestic sized facilities were used, 50\% of the potential could be captured, and that it would be spread out over a large number of rural users. Figure 1 also shows that $25 \%$ of the AD energy capacity could be captured at only a few $-10 \%$ - of the (larger) farms.

\subsection{Survey results for poultry farms}


The poultry population of Gazipur was surveyed via random choices of 25 poultry farms in each of 5 sub-districts. The survey results for the 439,950 birds over a total of $\mathrm{N}=125$ farms are summarised in Table 4 and Figure 2.

Table 4 The number of poultry farms with different sized flocks (from survey results, $N=125$ ) in Gazipur district.

\begin{tabular}{ccc}
\hline Number of Birds & Number of Poultry Farms & \% of Poultry Farms \\
\hline$<1000$ & 15 & 12 \\
$1000-2000$ & 55 & 44 \\
$2001-3000$ & 15 & 12 \\
$3001-4000$ & 10 & 8 \\
$4001-5000$ & 8 & 7 \\
$5001-10000$ & 13 & 10 \\
$>\mathbf{1 0 0 0 0}$ & $\mathbf{9}$ & 7 \\
Total & $\mathbf{1 2 5}$ & $\mathbf{1 0 0 \%}$ \\
\hline
\end{tabular}

From Table 4 it can be shown that $76 \%$ of the poultry farms have a poultry population of 4,000 or less. In terms of cumulative quartiles, $25 \%$ of the farms surveyed had a bird population of $<1,000$ birds, $50 \%$ had $<1,900$ birds and $75 \%$ of the farms had a bird population of $\leq 4,000$. The highest bird population found was 20,000 birds.

Table 5 shows the distribution of smallholdings by potential AD plant size. Only $7 \%$ of the farms are suitable for domestic sized biogas plant, showing an average capacity of 93 MJ/farm. Most (63\%) of the poultry farms are suited for a medium sized AD plant, showing 
an average energy capacity of $270 \mathrm{MJ} /$ day. A further $30 \%$ of the poultry farms are suitable for a large AD plant, averaging 1,400 MJ per day which could be suited for commercial or small industrial use.

Table 5

Distribution of poultry farms by AD plant size (from survey results, $\mathrm{N}=125$ ) in Gazipur district

\begin{tabular}{lcccc}
\hline & Biogas yield & & Average no. & Average \\
AD Type & $\mathbf{m}^{\mathbf{3}}$ & \% of farms & birds/farm & MJ/farm \\
\hline Domestic & $2-5$ & 7 & 572 & 93 \\
Medium & $5-25$ & 63 & 1614 & 270 \\
Large & $25-150$ & 30 & 8305 & 1399 \\
\hline
\end{tabular}

Given that $44 \mathrm{MJ}$ of energy is considered the requirement for domestic cooking for a medium sized family, Table 5 suggests the average farms suited for 'domestic' sized AD plants would actually be producing enough gas for two families (93 MJ/ day). Thus, such farms could in practice provide energy to another family, or develop some new entrepreneurial activity based on it. Similarly, most of the poultry farms have the potential for medium or largescale AD which could provide cooking gas for many families, or make significant contributions to businesses located on site or nearby. 


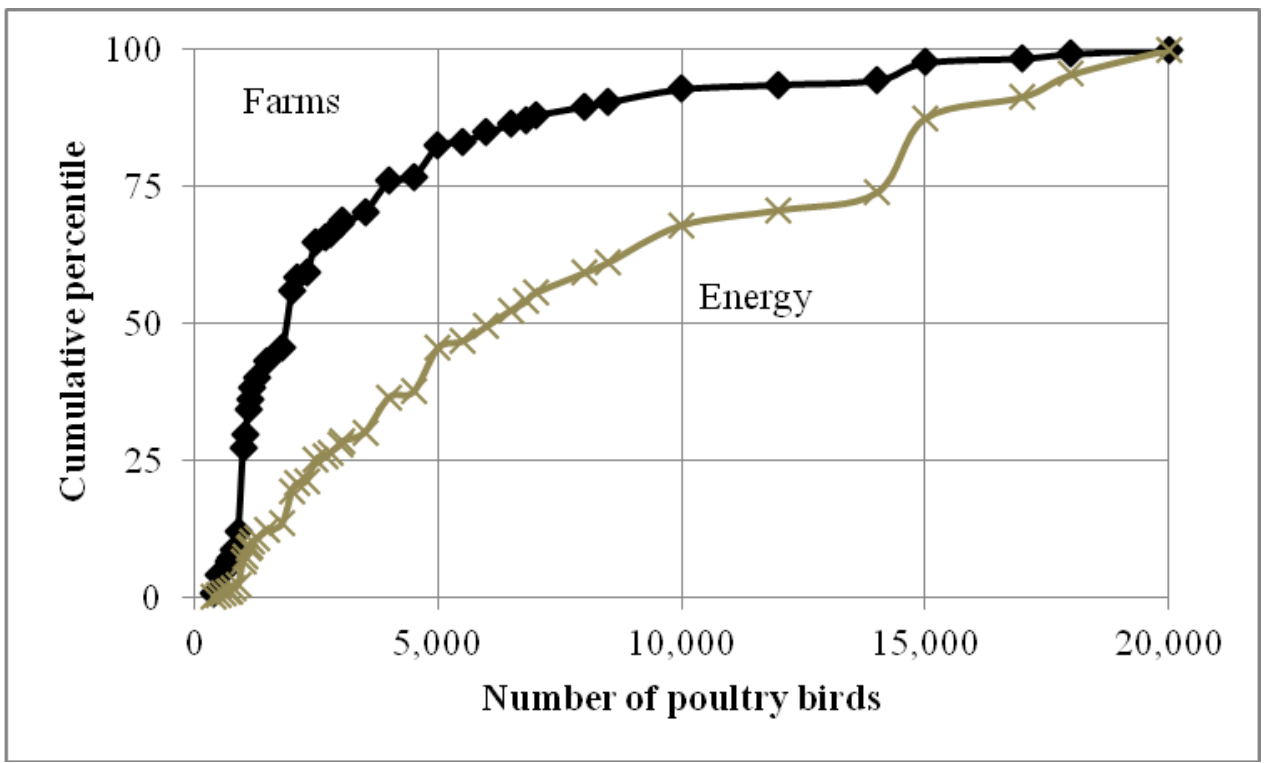

Figure 2. Cumulative percentile of the number of poultry farms and their energy potential with respect to the number of birds on each farm, for Gazipur district (from survey results).

Figure 2 introduces cumulative information not only for the flock sizes but also for the potential energy outputs. It is useful for determining which sized farms and thus sizes of AD plant should be targeted for different reasons. For example, it shows that most of the energy $60 \%$ - can be captured from as few as $25 \%$ of the farms (the largest ones), using large scale plants.

\subsection{Survey results of cattle markets}

All the known cattle markets in Gazipur district, $\mathrm{N}=30$, were surveyed to determine the number of cattle they serviced and the tonnage of waste rice straw bedding they produced daily. On average, each daily market had 796 cattle and produced 28 tonnes of waste i.e. $35 \mathrm{~kg}$ per head of cattle daily. Cumulative percentile figures were calculated to show that $25 \%$ of the markets had a cattle population of $\leq 400 ; 50 \%$ had a cattle population of $\leq 500$ and $75 \%$ had cattle populations of $\leq 1,000$ respectively. The highest cattle market population was found to be 2,000 . 
Table 6 shows the biogas yield and energy generating capacity of cattle market rice straw. Results indicated that each cow can produce $94 \mathrm{MJ}$ of energy, which is more than double that of an average-sized family's energy requirements for cooking. This number is considerably larger than one cow in a smallholding because all of the dung is collectable rather than being lost in the fields, and also there is a mass contribution from the rice straw used to feed and bed the cattle. The cattle at market were also in much better physical condition. In general, the potential energy generated from this source was shown to be very significant, so that even 'medium' sized AD plants were too small for this scenario. Instead, a new category of 'very large' AD plant had to be created to acknowledge the requirements. Nearly half of the markets required this new size of plant. This is an important finding of our work: that there exists an existing, regular, homogenous and suitable feedstock for AD production of biogas on a scale not previously developed, but typically present exactly where the need is for largescale - in towns. Thus, the energy could be used for businesses (such as those at the markets) or for easy distribution to local homes. The average energy capacity of these extra large AD plants is around 108,000 MJ.

Table 6

The distribution of cattle markets by potential AD plant size (from survey results, $\mathrm{N}=30$ ) for Gazipur district

\begin{tabular}{|c|c|c|c|c|}
\hline AD Type & $\begin{array}{c}\text { Daily Biogas Yield } \\
\mathbf{m}^{3}\end{array}$ & $\begin{array}{c}\% \text { of } \\
\text { markets }\end{array}$ & $\begin{array}{c}\text { Average } \\
\text { cattle/market }\end{array}$ & $\begin{array}{c}\text { Average } \\
\text { MJ/market }\end{array}$ \\
\hline Domestic/Medium & $\mathrm{n} / \mathrm{a}$ & 0 & & \\
\hline Large & $\begin{array}{l}1000-2000 \text { (Range different } \\
\text { for Cattle market rice straw) }\end{array}$ & 53 & 390 & 36,750 \\
\hline $\begin{array}{l}\text { Very Large } \\
\text { (new category) }\end{array}$ & $2000-7000$ & 47 & 1150 & 108,000 \\
\hline
\end{tabular}


The results show that the daily yield range of a cattle market is $1,000-7,000 \mathrm{~m}^{3} .53 \%$ of cattle markets have the capacity to produce $2,000 \mathrm{of}^{3}$ biogas daily. $10 \%$ of the cattle markets were found to have a biogas yield capacity of $\geq 7000 \mathrm{~m}^{3}$. Figure 3 represents cumulative information for both the sizes of the markets and the potential energy outputs. It shows that approximately $50 \%$ of cattle markets had 500 or fewer cattle and $25 \%$ had a cattle population of more than 1,000.

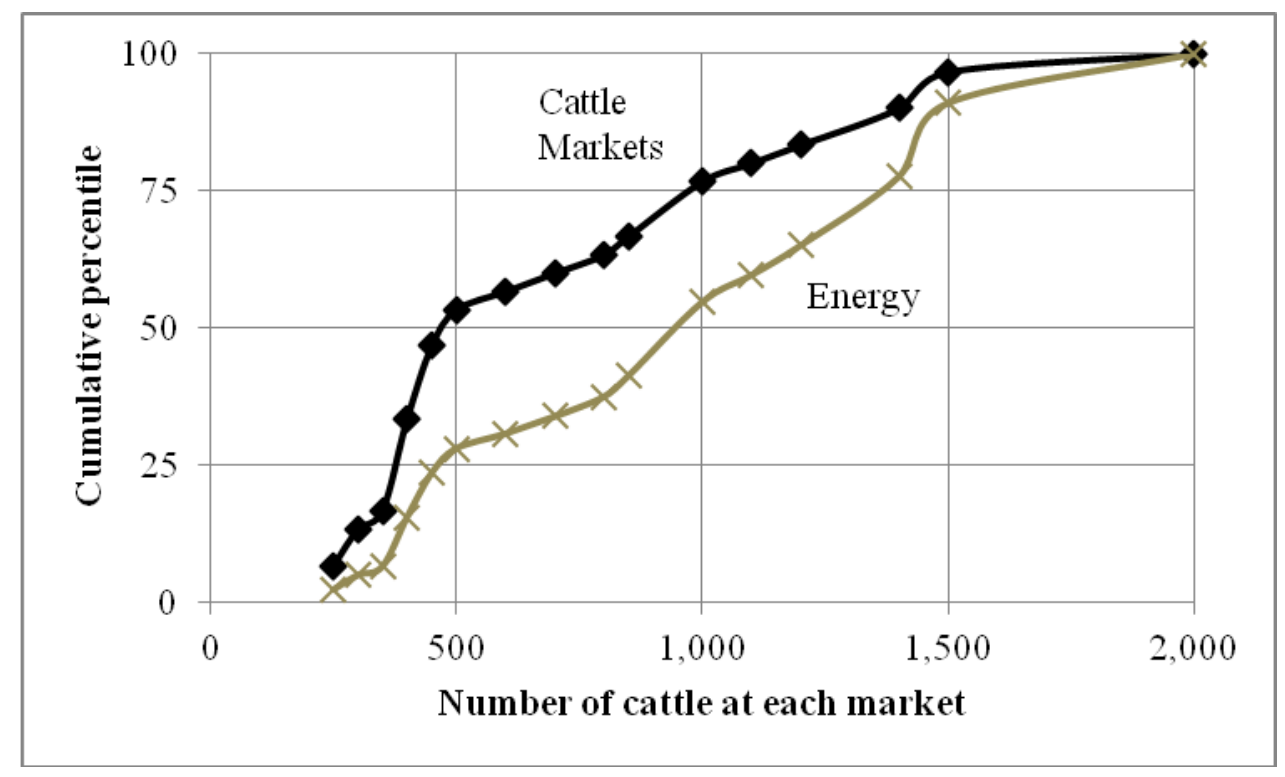

Figure 3. Cumulative percentile of the number of cattle markets and their energy potential with respect to the number of cattle in each, for Gazipur district (from survey results).

The total energy capacity of the cattle market rice straw feedstock from all 30 markets is 2,100,000 MJ, giving an average cattle market energy capacity of 70,000 MJ/ day. Such high numbers indicate that this feedstock has potential for not only biogas production but also secondary production of electricity.

\section{Scaling up to determine nationwide potentials}

The numbers obtained for the district of Gazipur were scaled up for the country of Bangladesh using multipliers based on the relative number of cattle, poultry and cattle 
markets in both. Table 7 below summarises the numbers of animals, which were obtained from the Division of Livestock Services in Dhaka and District Livestock Office in Gazipur.

Table 7

Numbers of livestock and markets in Gazipur and Bangladesh, and the multipliers they produced to scale up district results to national figures (DLO- District Livestock Office DLS- Division of Livestock Service)

\begin{tabular}{lccccc}
\hline & $\begin{array}{c}\text { Number } \\
\text { of cattle } \\
\text { (million) }\end{array}$ & $\begin{array}{c}\text { Number of } \\
\text { domestic cattle } \\
\text { (million) }\end{array}$ & $\begin{array}{c}\text { Number of } \\
\text { Poultry birds } \\
\text { (million) }\end{array}$ & $\begin{array}{c}\text { Number } \\
\text { of Cattle } \\
\text { markets }\end{array}$ & References \\
\hline $\begin{array}{l}\text { Gazipur } \\
\text { District }\end{array}$ & 0.86 & 0.74 & 24.82 & 30 & {$[25]$} \\
Bangladesh & 22.97 & 20.67 & 221.39 & 500 & {$[26]$} \\
Multipliers & 26.72 & 27.83 & 8.92 & 16.67 & \\
\hline
\end{tabular}

The difference in domestic cattle numbers versus general cattle numbers is due to commercial dairy livestock not being counted. It is worth noting that Gazipur appears to have different relative national shares of cattle compared to poultry or cattle markets [27]; these differences would be worth exploring before confidently using the results of this scaling up method. For example, the results suggest that in Gazipur the potential from poultry farms is much more frequent than the rest of the country on average, and investment in these and related businesses in that district might provide better returns on investment (time, research and money) than elsewhere. Similarly, Gazipur seems to have a large number of markets per head of cattle, compared to the rest of the country: for interested investors, it might be particularly beneficial to concentrate on appropriate AD plant in Gazipur for that reason.

The multipliers in Table 7 (above) were used to scale up the results in Tables 3, 5 and 6 to yield the national estimates shown below in Table 8 . There are several notable points. Firstly, the numbers of potential plants are huge: 2.3 million using domestic cattle dung alone. The large number implies the large number of households - almost one-to-one - which could benefit from cooking and lighting from AD. The disadvantages include the difficulty in setting up so many plants, including financing, expertise and maintenance issues. 
Table 8

The numbers of potential AD plant units for different feedstock in Bangladesh, broken down into percentages by size for each feedstock

\begin{tabular}{|c|c|c|c|c|c|c|}
\hline & $\begin{array}{l}\text { Small } \\
\left(<2 \mathrm{~m}^{3}\right)\end{array}$ & $\begin{array}{c}\text { Domestic } \\
\left(2-5 \mathrm{~m}^{3}\right)\end{array}$ & $\begin{array}{c}\text { Medium } \\
\left(5-25 \mathrm{~m}^{3}\right)\end{array}$ & $\begin{array}{l}\text { Large (25- } \\
\left.150 \mathrm{~m}^{3}\right)\end{array}$ & $\begin{array}{c}\text { Extra large } \\
\left(>150 \mathbf{~ m}^{3}\right)\end{array}$ & Totals \\
\hline Cattle & $\begin{array}{c}670,000 \\
(29 \%)\end{array}$ & $\begin{array}{c}1,341,000 \\
(58 \%)\end{array}$ & $\begin{array}{c}300,000 \\
(13 \%)\end{array}$ & $\mathrm{n} / \mathrm{a}$ & $\mathrm{n} / \mathrm{a}$ & $\begin{array}{c}2,311,000 \\
(100 \%)\end{array}$ \\
\hline Poultry & $\mathrm{n} / \mathrm{a}$ & $\begin{array}{l}4,403 \\
(7 \%)\end{array}$ & $\begin{array}{l}39,628 \\
(63 \%)\end{array}$ & $\begin{array}{l}18,871 \\
(30 \%)\end{array}$ & $\mathrm{n} / \mathrm{a}$ & $\begin{array}{c}62,902 \\
(100 \%)\end{array}$ \\
\hline $\begin{array}{l}\text { Cattle market } \\
\text { rice straw }\end{array}$ & $\mathrm{n} / \mathrm{a}$ & $\mathrm{n} / \mathrm{a}$ & $\mathrm{n} / \mathrm{a}$ & $\begin{array}{c}265 \\
(53 \%)\end{array}$ & $\begin{array}{c}235 \\
(47 \%)\end{array}$ & $\begin{array}{c}500 \\
(100 \%)\end{array}$ \\
\hline $\begin{array}{l}\text { Total numbers } \\
\text { of units }\end{array}$ & $\begin{array}{c}670,000 \\
(28 \%)\end{array}$ & $\begin{array}{c}1,345,403 \\
(57 \%)\end{array}$ & $\begin{array}{c}339,628 \\
(14 \%)\end{array}$ & $\begin{array}{l}19,136 \\
(14 \%)\end{array}$ & $\begin{array}{c}235 \\
(<1 \%)\end{array}$ & $\begin{array}{l}2,374,402 \\
(100 \%)\end{array}$ \\
\hline
\end{tabular}

\section{Discussion of planning implications of the data}

There are fewer poultry farms, but they are more appropriately serviced by medium and large plants able to provide for many families each. There are only 500 cattle markets expected nationally, but each with such a large capacity that commercial uses and electricity generation become competing options to householder cooking gas supply.

The breakdown by plant size is also useful for consideration. For example, the vast majority of all domestic plants would use cattle feedstock, implying that size might benefit from some specialised design features to make it more user-friendly and effective. For poultry, most of the plants must be medium-sized, so it might be worthwhile to modify designs for poultry litter use - but then it can be noted that almost ten times as many units are needed for cattle feed. Thus either of the two designs can develop, or, if necessary, the design might need to be dominated by the needs of cattle dung users. The same arguments apply to large units for poultry and cattle markets. 
Viewing the same data from the perspective of which types provides the most energy gives a different picture. Table 9 below shows how domestic cattle make up $97 \%$ of the number of $\mathrm{AD}$ plant units required, but on a per-unit basis the cattle market $\mathrm{AD}$ plant will provide much more energy, as illustrated in Figure 4. Thus, if an optimisation of energy is preferred for investment of time, resources or research, then cattle market plants might be the best starting point. This might be true for financiers desiring significant financial returns at fewer sites. On the other hand, to have a direct impact on the largest number of families, domestic plants running on cattle dung would be higher priority, and plans for financing, regulating and maintenance would have to be made - bearing in mind the circumstances of many smallholder families.

Table 9 illustrates the results categorised by feedstock source, showing the potential number of $\mathrm{AD}$ plants from cattle smallholdings, poultry farms and cattle market rice straw (larger numbers have been rounded).

Table 9

Potential AD in Bangladesh categorised by potential feedstock and (i) by AD plant number and ii) by energy contributions. Absolute numbers are 2.4 million units and 240 million MJ daily, respectively

\begin{tabular}{lcc}
\hline Feedstock & $\begin{array}{c}\text { Percentage of total AD plant } \\
\text { by number of units }\end{array}$ & $\begin{array}{c}\text { Percentage of total AD } \\
\text { energy contribution by } \\
\text { feedstock type }\end{array}$ \\
\hline Cattle & $97 \%$ & $70 \%$ \\
Poultry & $3 \%$ & $16 \%$ \\
Cattle market rice straw & $0.02 \%$ & $14 \%$ \\
& & $\mathbf{1 0 0 \%}$ \\
Total & $\mathbf{1 0 0 \%}$ & \\
\hline
\end{tabular}



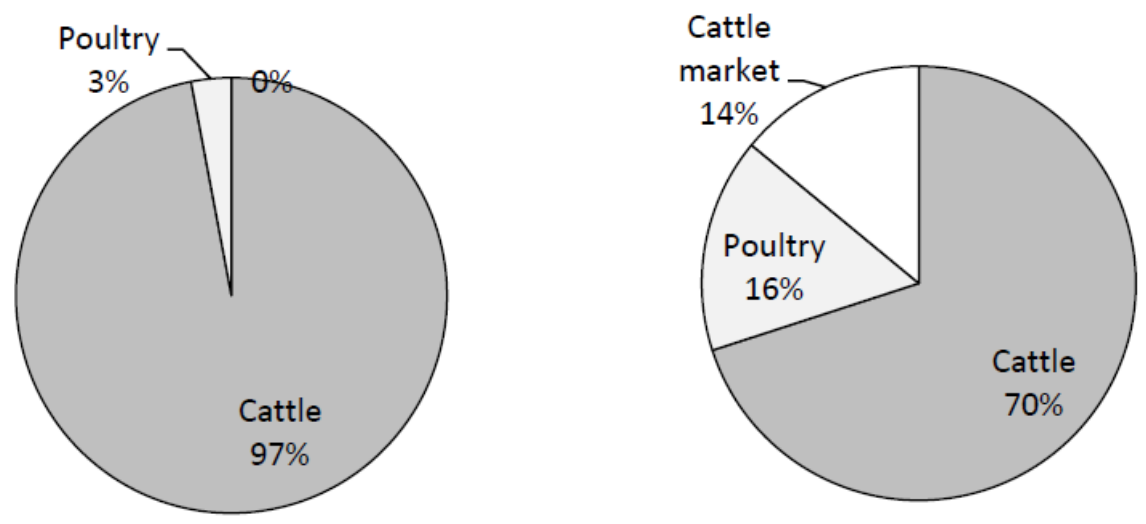

Figure 4. An illustration of the difference in distributions of AD plant when considered in terms of a) unit numbers and b) percentage contributions to energy nationally

Combining the AD capacity of three potential AD feedstocks, the daily potential AD capacity of Bangladesh is 240 million MJ which could come from $10.43 \times 10^{6} \mathrm{~m}^{3}$ of biogas $\left(1 \mathrm{~m}^{3}\right.$ biogas equals $\left.23 \mathrm{MJ}\right)$. This means the annual AD potential for Bangladesh from those potential feedstocks is $8.76 \times 10^{10} \mathrm{MJ}$ or $2.4 \times 10^{10} \mathrm{KWh}$.

\section{$6 \quad$ Final Overview}

The government of Bangladesh has a target to generate $5 \%$ of its total electricity using renewable energy technologies by 2015 and $10 \%$ by 2020 [28]. Ensuring that the potential of AD biogas production is fulfilled can play a vital role in meeting this target. A comparison between the potential AD capacity and the present reality is shown in Table 10 .

Table 10

Potential AD capacity is compared with the current status of AD

\begin{tabular}{lcc}
\hline Feedstock/Factor & Potential AD plant capacity & Current status \\
\hline Cattle dung & $2,310,000$ & 35,000 \\
Poultry litter & 63,000 & 5,000 \\
Cattle market rice straw & 500 (large and extra-large) & 0 \\
Total & $2,400,000$ & 40,000 \\
Present AD plant capacity (\%) & & $\mathbf{1 . 6 7}$ \\
Present AD energy capacity (\%) & & $\mathbf{0 . 6 7}$ \\
\hline
\end{tabular}

All of the results in the sections above provide crucial information for planning for businesses, civic authorities and national policy making. By considering these results and information, the government can plan, NGOs and international development organizations 
can take initiatives, investors can see the relevance of funding, and the documentation of the GWP impact can assist in getting CDM credit. Integration of all these efforts could make a realistic opportunity for $\mathrm{AD}$ energy generation with sustainable management.

\section{$7 \quad$ Conclusion and recommendation}

\subsection{Conclusion}

This paper presents important primary data from surveys to determine the potential of common feedstocks for AD in Bangladesh. Domestic cattle in smallholdings, commercial poultry farms and daily cattle markets were surveyed and the results are presented in a matrix manner that allows interrogation by size, by feedstock, by number and by commercial/ domestic use potential (see section 6). The annual AD potential from those potential feedstocks is $8.76 \times 10^{10} \mathrm{MJ}$ or $2.4 \times 10^{10} \mathrm{KWh}$, which is enough to meet the cooking needs of 6 million rural households (30 million people). The richness of the data provides invaluable information for strategic planning

Headline results include:

- As many as 2.3 million households could have their own units for lighting and cooking, and could potentially be set up via micro-financing

- 340,000 medium sized units could provide business/ entrepreneurial use

- 19,000 units could provide large scale provision or electricity production

- As few as 500 large/very large units based at cattle markets could capture $14 \%$ of the overall potential from these feedstocks 
This is the first investigation of the feedstock from waste straw and dung from cattle markets in Bangladesh. It is identified here as a novel. significant and potentially very useful feedstock.

\subsection{Recommendations for further work}

A more critical analysis of realistic factors affecting biogas and methane yield should be undertaken for cattle market rice straw as a feedstock. Biogas and methane yields were determined in this research for rice straw that contained $15-20 \%$ of dung. The yield could be investigated using this feedstock with different percentages of cattle dung mixed with it. A significant amount of cow urine is mixed with cattle market rice straw waste.

Analysis of other feedstock types, such as food waste, water hyacinth, MSW and wastes mixed with animal manure, should be undertaken. The biogas yield capacity of these feedstocks, with different ratios of pre-mixing, could be investigated. A feasibility study could be undertaken to find out the barriers and bottlenecks of the implementation of AD program in Bangladesh utilizing various feedstocks. Further research could also investigate the efficiency of existing AD units.

It is important to undertake a detailed financial and social impact assessment of the various sized $\mathrm{AD}$ plants in order to understand the possible impacts on the rural population. The practical financial tools (e.g. microfinance) which could work for such a biogas program in Bangladesh should be determined in detail.

Similar studies could be carried out for similar developing countries with rural areas; this work showed that it is feasible and effective for such a study to systematically determine the information gaps and lead to very useful information for future planning, both in detail and for an overview, for financial, environmental and social impacts.

More work on life-cycle analysis, global warming potential, energy savings and baseline calculations of AD should be carried out to give a clear idea about the Certified Emission Reduction (CER) of $\mathrm{AD}$, building on the work set out here; this is likely to eventually allow use of the Clean Development Mechanism.

\section{References}


[1] Islam MS. Use of bio-slurry as organic fertilizer in Bangladesh agriculture. Report prepared for presentation at the International Workshop on the Use of Bio-slurry from Domestic Biogas Plant, Bangkok, Thailand, 27-28 September 2006. Amsterdam: SNV Netherlands Development Organisation; 2006.

[2] International Monetary Fund. Global Monitoring Report: Population Figures for Bangladesh; 2008.

[3] World Bank. Market assessment survey of solar PV application in Bangladesh: final report. Dhaka, Bangladesh: World Bank; 2005.

[4] Asian Development Bank. Key indicators of developing Asian and Pacific countries. 2nd ed. Oxford: Oxford University Press; 2001.

[5] International Energy Agency (IEA) Statistics Division. Energy and resources electricity: electricity consumption per capita. [Online]. Available: http://earthtrends.wri.org/text/energy-resources/variable-574.html; 2011.

[6] SNV, a survey of Netherlands Development Organisation, Biogas Practice Team on feasibility of a national programme on domestic biogas in Bangladesh. Amsterdam, The Netherlands: SNV Netherlands Development Organisation; 2005.

[7] Sinha AHMM, Enayetullah I. Waste Concern and worldwide recycling: financing Dhaka market composting with public-private partnerships and carbon credits. In: United Nations Human Settlements Programme, UN-HABITAT, editors. Solid waste management in the world's cities, London \& Washington, D.C.: Earthscan; 2010, p. $117-23$.

[8] Choudhury RCM. Draft report of the inaugural meeting on the regional 3R forum in Asia, 11-12 November, 2009. In: United Nations Human Settlements Programme, UN-HABITAT, editors. Solid waste management in the world's cities, London \& Washington, D.C.: Earthscan; 2010, p. 106-10.

[9] Enayetullah I. A study of solid waste management for environmental improvement of Dhaka City. Unpublished Master of Urban \& Regional Planning thesis. Dhaka, Bangladesh: Bangladesh University of Engineering \& Technology (BUET) Department of Urban \& Regional Planning; 1995.

[10] Dhaka City Corporation. Dhaka City state of environment report. Dhaka, Bangladesh: Dhaka City Corporation; 2004.

[11] Biswas WK, Lucas NJD. Economic viability of biogas technology in a Bangladesh village. Energy 1997; 22:763-70. 
[12] Goyal S, Dhull SK, Kapoor KK. Chemical and biological changes during composting of different organic waste and assessment of compost maturity. Bioresource Technology, 2005; 96, 1584-1591.

[13] Pfammatter R, Schertenleib R. Non-governmental refuse collection in low-income urban areas. Lessons learned from selected in Asia, Africa and Latin America. SANDEC Report No.1/96.Water and sanitation in developing countries. Duebendrof, Switzerland: EAWAG/SANDEC; 1996.

[14] Körner I, Visvanathan C. Biological treatment. In: Solid waste management in Asia. http://www.tu-harburg.de/aws/asialink/ TETRAWAMABOOK06112006S. pdf and DVD, self published, Hamburg, Germany: Hamburg University of Technology, 2006; Chapter 4, 87-114.

[15] UK Government Department for Food and Rural Affairs (DEFRA). Government review of waste policy in England 2011. London: DEFRA; 2011, p. 64-8.

[16] Gofran MA. Biogas technology. Dhaka, Bangladesh: Grameen Shakti, 2008, p. 121.

[17] Bangladesh Centre for Advance Studies. Feasibility study on biogas from poultry droppings (unpublished document). Dhaka, Bangladesh: Bangladesh Centre for Advance Studies; 2005.

[18] Waste Concern. Final report on CDM project potential in the poultry waste management sector in Bangladesh. http://www.wasteconcern.org/Publication/Poultry \%20Final.pdf, 2005.

[19] Gofran MA. Status of biogas technology in Bangladesh. Published in The Daily Star On: 2007-09-05. http://www.thedailystar.net/story.php?nid=2631; 2007.

[20] BBS (Bangladesh Bureau of Statistics). Statistical year book of Bangladesh. Dhaka, Bangladesh: Planning Division, Ministry of Planning Government of the People's Republic of Bangladesh; 2009.

[21] Wilson DC, Adebisi OA, Kaine C, Christopher RC. Building recycling rates through the informal sector. Waste Management, 2009; 29:629-35.

[22] Haq S., Interview with Shamsul Haq, Former Director, Bangladesh Centre for Scientific and Industrial Research (BCSIR); 2010.

[23] IDCOL, IDCOL and SNV Biogas plant construction manual for "National Domestic Biogas and Manure Program; 2008.

[24] Gofran MA. Biogas technology. Dhaka, Bangladesh: Grameen Shakti, 2008, p. 81. 
Prepared for submission to "Renewable and Sustainable Energy Reviews"

[25] District Livestock Officer (DLO), Report from District Livestock Office, Gazipur; 2010.

[26] DLS, An overview of Department of Livestock Services, Dhaka, Bangladesh; 2009.

[27] Gofran MA. Biogas technology. Dhaka, Bangladesh: Grameen Shakti, 2008, p. 85.

[28] Renewable energy policy. Ministry of Power, Energy and Mineral Resources. Dhaka, Bangladesh; 2008.

[29] Chowdhury R., Consultant Engeneer, Advance Engeneering, Dhaka, Bangladesh. Personal communication; 2010. 